\title{
Introduction to the Special Issue
}

\section{Vocational rehabilitation considerations for people with emerging disabilities}

\author{
Phillip D. Rumrill Jr ${ }^{\mathrm{a}, *}$ and Lynn C. Koch ${ }^{\mathrm{b}}$ \\ ${ }^{a}$ Kent State University, Center for Disability Studies, Kent, OH, USA \\ ${ }^{\mathrm{b}}$ University of Arkansas, Fayetteville, AR, USA
}

Revised/Accepted August 2017

Bridget is a 32 year-old African American woman who works as a Claims Manager for a large automobile insurance company. She holds a bachelor's degree in Business Administration and Finance. Bridget's job requires her to review, evaluate, and approve collision and liability claims following motor vehicle accidents and other circumstances that cause damage to covered vehicles. As part of that process, she verifies benefits and levels of insurance coverage, negotiates with other insurance companies and drivers insured by her company regarding damage estimates and repair costs, and prepares claim records and other documents for litigation. Most of her work is performed over the telephone or using the computer, but she is sometimes required to meet with claimants and other parties to insurance claims in person. Bridget works full-time, 40 hours per week, on a 12-month basis. Her job requires regular but not extensive automobile travel and airplane travel to her company's corporate headquarters in Connecticut three or four times per year.

Bridget was recently diagnosed with RelapsingRemitting Multiple Sclerosis (MS), an inflammatory auto-immune disease of the central nervous system that has significantly increased in incidence over the past two decades in the general population and

\footnotetext{
*Address for correspondence: Phillip D. Rumrill, Jr, Kent State University, Center for Disability Studies, P.O. Box 5190, 405 White Hall, Kent, OH 44242-0001, USA. Tel.: +1 330672 0600; Fax: +1 330672 2512; E-mail: prumrill@kent.edu.
}

especially among African Americans. She has two or three exacerbations of MS each year, which are characterized by periods of extreme fatigue, numbness and tingling in her left (dominant) hand, gait problems, and problems with short and long-term memory. During her exacerbations, which come on without warning and may last up to three weeks, Bridget uses accrued sick leave when she is unable to work, a quad-cane for mobility, and several memory enhancement and planning/organizational applications for her iPad. In fact, she has taken to using the iPad "apps" at all times. When Bridget experiences fatigue during her exacerbations, she sometimes takes an extended lunch break during which she rests quietly in her office. Her supervisor also allows her to work from home on days when she is too tired to come into the office. Bridget has disclosed her MS to her supervisor and to her co-workers, and she reports that they have been very supportive.

Bridget receives mental health counseling from a licensed psychologist to assist her in the adjustment to MS, sees a neurologist at a nearby MS clinic twice a year, and is in frequent contact with a counselor at the state Vocational Rehabilitation office. She also contacted the Job Accommodation Network soon after she was diagnosed with MS for assistance in identifying and requesting reasonable accommodations from her employer. Bridget and her partner are actively involved in an MS support group, which meets twice a month at a local church. 
Like many other Americans with emerging disabilities (i.e., conditions that are either new to medical science or are increasing in incidence and prevalence), Bridget is a productive and well-trained worker who has much to contribute to the labor force. She hopes to work through to retirement age, and to that end she consults her neurologist regularly and adheres strictly to her medication regimen. Thanks to advances in medicine, assistive and general usage technology, and Federal laws protecting workers with disabilities and entitling them to reasonable accommodations at work, Bridget's long-term career prospects appear to be good.

Many people with emerging disabilities share with Bridget a strong work ethic and a desire to continue working as time and their conditions progress, but research clearly documents the difficulties that people with emerging disabilities often face in the world of work. First and foremost among these difficulties are the anxiety and uncertainty that many individuals with emerging disabilities experience regarding their capacity to enter or retain employment. Career anxiety is especially prevalent for individuals at the time of diagnosis or as symptoms go undiagnosed and worsen during the prolonged process of seeking an accurate diagnosis. Uncertainty about one's capacity to work is often intensified for individuals like Bridget who have episodic and progressive conditions. Additional difficulties include invalidation of the person's medical and psychological symptoms by family members, friends, and health care providers; negative attitudes on the part of employers and coworkers; difficulties in arranging transportation to and from work; functional limitations associated with the person's medical condition; the unpredictability of many conditions in terms of their impact on daily functioning; the invisible nature of many emerging disability symptoms (which makes it difficult for others to understand the person's disability experience); the limited availability of disability benefits such as long-term disability insurance and Social Security Disability Insurance; and lack of access to assistive technology and other on-the-job accommodations. Studies also show that women, members of racial or ethnic minority groups, people with lower levels of education, those with more severe and persistent symptoms (especially chronic pain), younger individuals, and older individuals are more likely than other people to experience career-related problems following the onset of emerging disabilities.

By their own reports, people with emerging disabilities are worried about their long-term employment prospects. Surveys of people with emerging disabilities in a number of countries repeatedly document concerns related to workplace discrimination, the need for assistance in weighing the risks and benefits of employment, the need for information regarding home-based employment, interest in learning more about legal protections and employment-related resources, issues surrounding health insurance coverage and access to quality health care, the need for more widespread availability of assistive technology in the workplace, and the desire for more effective self-advocacy strategies to aid in employment and community participation.

Vocational rehabilitation professionals are uniquely qualified to provide many of the services and supports that people with emerging disabilities need in making career-related decisions and in their efforts to seek, secure, and maintain employment. However, people with emerging disabilities are often underserved by the state-Federal Vocational Rehabilitation program and by private-sector rehabilitationists. Consequently, people with emerging disabilities represent a clientele whose needs must be better understood by rehabilitation researchers, policymakers, educators, and practitioners.

To that end, the articles in this special issue address a wide range of medical, psychosocial, and vocational issues facing people with emerging disabilities. Current research findings regarding the employment and quality of life of people with emerging disabilities are featured, and we hope that $J V R$ readers will take interest in the growing body of knowledge concerning the characteristics and needs of people with emerging disabilities. We wish to thank Dr. Paul Wehman, Editor of $J V R$, for the opportunity to develop this special issue. Our fellow contributors and we are very pleased to share our work in this forum, and we welcome any and all feedback regarding the relevance of these articles to the field of Vocational Rehabilitation. 